species had a breeding.place near which any whaling ship, in the present century at least, ever went ; and ihose who accept this version recur to errors that were refuted by Prof. Stenstrup more than five-and-thirty years ago. ALFRED NEWTON.

Magdalene Coll ege, Cambridge, March 10.

\section{The Decomposition of Liquids by Contact with} Cellulose.

THE recent work of Dr. Gore, on "The Decomposition of Liquids by Contact with Powdered Silica," presents a striking resemblance to what has from time to time been a:certained with such substances as cellulose. In fact, the properties ascribed to silica are very likely shared under some conditions by colloids in general, whether they be "organic" or "inorganic" bodies. Cellulose, when immersed in diluted solutions of some metallic salts, has the power of abstracting from them a certain quantity of the salt for which it may have no chemical affinity as ordinarily understood. The amount of salt abstracted is dependent upon several conditions: the degree of dilution of the salt; the ratio of cellulose to salt; the ratio of cellulose to weight of solulion; the temperature; the physical condition of the cellulose; and the chemical constitution of the cellulose.

Let us, in order to eliminate the last-named condition, confine ourselves to pure cellulose or cotton. When cotton wool is placed in a solution of a metallic salt, it abstracts the salt from the solution until equilibrium is established. If we regard the part played by the cellulose in the light of Witt's theory of solid solution, the amount of salt retained by cellulose is con. ditioned by the relative solubility of the salt in water and cellulose, and the ratio in which the three exist together, If water is now added, a certain amount of the salt dissolved by the cellulose will become resoluble in the water. Also, if the solution be concentrated, the fibre will generally take up a further quantity. In some cases, however, the amount of salt taken up by the cellulose is not imparted to the solution on dilution. This is probably due, as in the case, I believe, of the ferric salts, to dissociation in solid solution. The dissociated base being insoluble (in water) is retained by the cellulose on addition of water, whereas the acid may be dissolved. The physical condition of the same cellulose has a great influence upon the amount of salt which it is capable of dissolving. If cellulose be finely disintegrated, it behaves differently from that in which the ultimate fibres remain intact.

The cotton fibre, when seen under the microscope, is found to vary considerably in shape and size. It is probable, then, that each fibre has a certain constant of absorption peculiar to itself. Cellulose, when rendered anhydrous by placing it in a water-bath or desiccator, is found to rise considerably in tem. perature when exposed to a damp atmosphere. This may, however, be caused by the liberation of heat, due to the condensation of moisture from the gaseous state. If so, no rise of temperature would be noticed in plunging anhydrous cellulose into water. It appears, however, that cellulose is susceptible of a certain degree of hydration in coming in contact with water, which is probably attended by the liberation of heat. I have found that dried cellulose placed in a damp atmosphere remains at a higher temperature than its surroundings so long as it is takin up moisture, which appears to be greatest when the rate of absorption is greatest. By the time it has recovered its normal condition of moisture it has sunk to the temperature of its surroundings.

The above considerations seem to point out that cellulose, like silica, exhibits well the phenomena of solid solution.

C. BeAdle.

Physiological Psychology and Psycho-physics.

IN a note contained in your issue of January II (p. 252), upon the teaching of psycho-physiology in University College, I notice two errors; which, as they are, unfortunately, very wide spread, you will perhaps allow me to correct.

(1) "Physiological psychology" and "psycho-physics" are not one and the same thing. The former science is a specially limited and specially enlarged psychology. Limited : in that it pays more attention to experimentation carried out by physi. ological methods than to any other psycholorical experimenta. tion. Enlarged : in that it discusses the most important problems relating to the physical basis of mental life. These latter problems belong to psycho-physies, which is the science of the relation of "mind" to " body."

NO. I 272 , VOL. 49]
(2) A "practical course in psycho-physiology," which confines itself to the senses, is not a representative or adequate course, as the note implies. The psycho-physics of sensation is no more the whole of psycho-physics than the physiology of the sense-organs is the whole of physiology, or the psychology of sensation, perception, and idea, is the whole of psychology. A historical accident has led to this popular restriction of the term ; but a glance at the literature of the science will show its wrongness.

Cornell University, February 16.

E. B. TITCHENER.

DR. Titchener's criticism of my note strikes me as a little strange. First of all, he objects to my speaking of "physiological psychology or psycho-physics," maintaining that they are different, and then proceeds at once to subsume psycho physics under physiological psychology. As a matter of fact, psycho-physics, as understood by Fechner, the coiner of the word, and generaily up to quite recent times, does not directly refer to the relaticn of the organism to psychical phenomena at all, but to the relation between the (extra-organic) stimulus and sensatior, though of course this inquiry leads on to two further inquiries: (a) the relation of the extra-organic to the organic process, and (b) the relation of this last to sensation. Muinsterberg and others now use "psycho-physical" for relations generally between neural processes and psychical processes, but the change of meaning is a little confusing. Anyhow, it will be seen that there is no general agreement about the expressions "physiological p cych logy" and "psycho-physics," such as Dr. Titchener's note suggests.

I may add that in using "or" rather loosely (as I felt justified in doing in a short note), I did not mean to imply that the two branches of inquiry were identical. I wanted to call attention especially to the fact that the course would go systematically over an experimental inquiry into the senses which would necessarily include reference to stimulus, and so psychophysics, and reference to nerve process, and so physiological psychology. As to Dr. Titchener's second "error," I find him hypercritical. I am well aware that psycho-physiology covers more than the senses, and I think that no:hing which I say implies the contradictory of this. There can surely be a practical course on a subject which does not exhaust all divisions of the subject. As a matter of fact, however, Dr. Hill is taking up other branches, as reaction-time experiments. I was content to emphasise the fact that the senses would be systematically examined; and all who know what psycho-physiology bas done, know that by far the larger part of the really fruitful work lexding to definite results has been done in the investigation of the senses.

March 3.

THE Writer of THE Nute.

\section{THE LAST GREAT LAKES OF AFRICA.}

DMIRABLY translated as it is, this book scarcely re. tains a trace of its previous existence in a foreign tongue; but although the translator states in the preface that she has slightly condensed the original matter in bringing it to its present form, we believe that much more rigid compression might wisely have been applied. Earlier books have placed later travels in Eastern Equatorial Africa so prominently before the British reader, that much of the ground which was full of fresh interest when the two gallant Austrians traversed it is now familiar, and its features common place. Thus a great part of the first volume, detailing the troubles of inexperienced and, perhaps, somewhat imperious Europeans in organising a large caravan at Zanzibar and Pangani, and in crossing the coast-lands and ascending the slopes to Kikuyu, might well have been omitted without lessening the thrilling interest of subsequent chapters.

The expedition, primarily a sporting one, was also in large measure exploratory, and if the pursuit of big game, and the hairbreadth escapes of the hunters

1 Discovery of Lakes Rudolf and Stefanie. A Narrative of Count Samuel Teleki's Exploring and Hunting Expedition in Eastern Equatorial Africa in Tolekis Exon 1887 and 188. . By his companion, Lieut. Ludwig von Hohnel. Translated by Nancy Bell (N. W'Anvers). With ${ }^{179}$ original illustrations and five 